\title{
Health-Related Physical Fitness of School Going Girls in Indian Himalayan Region: An Analytical Survey
}

\author{
Tadang Minu ${ }^{1}$, Anil Mili ${ }^{1}$, Dipika Basumatary ${ }^{1}$, Vivek Kumar Singh ${ }^{1}$, Poli Borah ${ }^{2}$, \\ Hemantajit Gogoi ${ }^{3, *}$ \\ ${ }^{1}$ Department of Physical Education, Rajiv Gandhi University, Arunachal Pradesh, India \\ ${ }^{2}$ Department of Sports Biomechanics, Lakshmibai National Institute of Physical Education, Gwalior, India \\ ${ }^{3}$ Department of Sports Coaching, Sri Sri Aniruddhadeva Sports University, Chabua, India
}

Received September 16, 2021; Revised November 29, 2021; Accepted December 22, 2021

\section{Cite This Paper in the following Citation Styles}

(a): [1] Tadang Minu, Anil Mili, Dipika Basumatary, Vivek Kumar Singh, Poli Borah, Hemantajit Gogoi , "Health-Related Physical Fitness of School Going Girls in Indian Himalayan Region: An Analytical Survey," Universal Journal of Public Health, Vol. 9, No. 6, pp. 436 - 444, 2021. DOI: 10.13189/ujph.2021.090611.

(b): Tadang Minu, Anil Mili, Dipika Basumatary, Vivek Kumar Singh, Poli Borah, Hemantajit Gogoi (2021). Health-Related Physical Fitness of School Going Girls in Indian Himalayan Region: An Analytical Survey. Universal Journal of Public Health, 9(6), 436 - 444. DOI: 10.13189/ujph.2021.090611.

Copyright $\odot 2021$ by authors, all rights reserved. Authors agree that this article remains permanently open access under the terms of the Creative Commons Attribution License 4.0 International License

\begin{abstract}
Objective: Recently, Indian has adopted many policies to promote health, wellness and sports culture in the country. Though these policies have been implemented nationally, limited research is available about the health-related fitness status of children in the Indian Himalayan region. Therefore, the present study was conducted to survey the health-related fitness status of school-going girls in the Indian Himalayan region. Materials and methods: A total of 563 school-going girls had participated in the study, 166 were from the age group of 10-12 years, 164 from the age group of 13-15 years and 233 from the age group of 16-18 years. Administration manual of Khelo India Fitness Assessment in Schools-version 2.0 was followed for data collection for five health-related physical fitness components. Simple descriptive statistics and One-Way ANOVA test were employed as statistical tools for the study. Results: The study showed a moderate level of health-related fitness among school-going girls in the Indian Himalayan region. The height and weight of the participants were found at lower 50 percentiles as per the growth chart of IAP. One-Way ANOVA test and pairwise comparison revealed the presence of variance in the fitness components between different age groups. Conclusion: It was suggested to involve parents and elders to change the sedentary habits of the children. Proper execution of sports infrastructure development programmes can further help in promoting
\end{abstract}

health, wellness and sports culture in the region.

Keywords Physical Fitness, Himalayan Region, NEP 2020, Khelo India

\section{Introduction}

The Himalayan region is the vast mountain range that separates India from China (Tibet) along its north-central and north-eastern frontiers and stretches between latitudes $26^{\circ} 20^{\prime}$ and $35^{\circ} 40^{\prime}$ North and longitudes $74^{\circ} 50^{\prime}$ and $95^{\circ} 40^{\prime}$ East. The region is inhabited by various tribal communities and is in a diverse stage of development but they are still backward compared to other urban communities of Indian. The majority of the population in this region depends on agriculture for livelihood. Their daily life is composed of various informal physical activities for earning livelihood which helps them for better physical development. The children of this region grow up participating in such informal physical activities which helps them in better physical development compared to other regions' children [1].

A child's development begins from the day he is born. After a particular age, a child begins to learn and experience games and sports and starts participating in 
other enjoyable physical activities. Bull et al. [2] had recommended engaging the children between 5-17 years of age in at least 60 minutes of moderate to vigorous physical exercise each day. Although, Bull et al. [2] had suggested incorporating vigorous-intensity aerobic activities and endorsed regular activity of more than 60 minutes per day for extra health benefits; it is always recommended that the intensity of the activities must depend on the physical status and performance of the children $[3,4]$. It is expected that, by the time children become teenagers, they must be able to develop their body, muscles and bones to take part in specialised activities like climbing on playground equipment, playing basketball, jumping rope and learn to strengthen their muscles using various gym equipment etc. The development period of human life is the most critical and it shapes the future of an individual. Sometimes, a particular type of social influence may affect the behaviour of children and may lead to developing negative health behaviour and if not guided properly, may lead to an unexpected decline in health and social participation. In such cases, most girls are seen out of interest to participate in sports and physical activities. It is usually observed that girls are not provided equal opportunities to participate in sports and physical activities in comparison to their male counterparts [5]. More of it, the Indian social environment makes it easier for men to participate in sports and whereas makes it harder for girls to do so [6]. The general social environment has not only inhibited girls from participation in sports but has also ostracized them when they intend to participate. This difference can be seen in the facilities and programmes which are arranged for girls in schools and colleges. However, the time has changed and the situations are improving. A number of girls from the Indian Himalayan region have been defying the odds, bringing laurels to the country as well as to the local communities but still, there is a lot to be achieved.

It has been reported that there is a strong relationship between health and education. Recently NEP 2020 [7] has also proposed health-related interventions for proper nourishment and good health of children. In 2012, Draft NPEP [8] suggested that the Physical Fitness of every school-going child studying in class $\mathrm{V}$ and above, must be evaluated depending on six components: Cardio-Respiratory Endurance, Muscular Strength, Muscular Endurance, Flexibility, Explosive Strength and Body composition. It is necessary to assess health-related physical fitness in school children in order to develop programmes aimed at encouraging a healthy lifestyle, which includes regular physical activity and dietary improvement as critical strategies for combating overweight/obesity and its associated diseases [9,10]. Good health-related physical fitness is associated with a decreased prevalence of risk of illness, body fat, and mental and physical health problems, and lead to enhanced academic achievement $[11,12,13,14,15]$. Though such policies have been endorsed to evaluate the physical fitness of school-going children all over India, it is observed that limited research is available about the physical fitness status of school-going girls in the Indian Himalayan region. Therefore, the current study was conducted to survey the health-related physical fitness of school-going Girls in the Indian Himalayan region, which will enlighten the research community as well as open the door of possibilities for future research.

\section{Materials and Methods}

\subsection{Participants}

The study involved a total of 563 girls from the Indian Himalayan region out of whom 166 were from the age group 10-12 years, 164 from the age group 13-15 years and 233 from the age group 16-18 years. All the participants were school-going children from grade IV to grade XII. They were selected randomly from 40 different schools in the region. The study was conducted following the guideline set in the declaration of Helsinki [16]. The legal guardians of the participants had received a thorough description of the purpose of the study with the details of the involved test protocols and submitted their signed consent before the conduct of the tests.

\subsection{Variables}

The health-related physical fitness status of the school going girls were tested following the administration manual of Khelo India Fitness Assessment in Schools-version 2.0 [17]. As per the guideline in the administration manual of Khelo India Fitness Assessment in Schools-version 2.0, the participants were tested on a total of five health-related physical fitness components. They were: BMI, Speed, Endurance, Strength and Flexibility. These five components were also considered as the variables for the study.

\subsection{Selection and Administration of Test}

The participant's, height was measured using a standard Stadiometer (SECA model 213, Hamburg, Germany) while the unit of measurement was centimetre $(\mathrm{cm})$. To measure the weight of the participants a digital Flat Scale (SECA model 213, Hamburg, Germany) was used and the unit of measurement was kilogram $(\mathrm{kg})$. Further, BMI= body weight (kilograms) divided by height squared (meters) formula was applied to calculate the BMI of the participants. To measure the strength of the participants, the Modified Push-Ups for Girls test was used and the correctly completed number of push-ups was recorded for the purpose of the study. The flexibility of the participants was measured using Sit and Reach test and for the test, Sit and Reach Trunk Flexibility Box (Baseline 12-1085, White Plains, USA) was used. The flexibility was recorded in the 
unit $\mathrm{cm}$. To test the cardiovascular endurance of the participants 600 Meter Run/Walk test was used. The timing of the participants was recorded in the unit minute (min). To test the speed of the participants, 50 Mtr Dash test was used and timing was recorded in the unit second (s). For both the tests 600 Meter Run/Walk and 50 Mtr Dash; stopwatch, whistle, measuring tape and marker cones were used as tools and equipment.

The tests were conducted at the participant's school track and field area, and the timing for the tests was set during the physical education class. The test protocol started by measuring height and weight for calculating BMI followed by the test for speed. The protocol continued with the flexibility and strength test of the participants and was completed with the test for cardiovascular endurance.

\subsection{Statistical Analysis}

To identify the health-related fitness trend of school-going girls in the Indian Himalayan region, simple descriptive statistics were calculated. One-Way ANOVA test was applied to find the difference of fitness status between different age groups of the participants and LSD Post Hoc Multiple Comparison test was selected for pairwise comparisons among the groups [18]. Further Mean Plot was used to display the pairwise differences between the groups. All statistical calculations were done using IBM SPSS (Version 25) and the level of significance was set at $0.05(\mathrm{p}<0.05)$.

\section{Results}

A total of 563 school girls from the Indian Himalayan region had participated in the study. Out of them, 166 girls were from the age group of 10-12 years, 164 from the age group of 13-15 years and 233 girls from the age group of 16-18 years. The descriptive statistics of the demographic variables (Table 1) revealed that the average height and weight of 10-12 years age group girls were 143.08 \pm 7.97 $\mathrm{cm}$ and $37.27 \pm 5.58 \mathrm{~kg}$, the average height and weight of $13-15$ years age group girls were $148.80 \pm 4.33 \mathrm{~cm}$ and $45.41 \pm 4.61 \mathrm{~kg}$ and the average height and weight of 16-18 years age group girls were $150.67 \pm 5.90 \mathrm{~cm}$ and $48.97 \pm 3.15$ $\mathrm{kg}$ respectively.
The descriptive statistics of the physical fitness variables (Table 2) revealed that the BMI of girls of the age group 10 -12 years $(17.93 \pm 1.14)$ was lower compared to the age groups 13-15 years $(20.41 \pm 1.74)$ and $16-18$ years $(21.58 \pm 1.36)$. Further, the applied One-Way ANOVA test $(\mathrm{F}=320.83, \mathrm{p}=0.00)$ (Table 3) reveals that there was a significant difference in mean BMI among the three groups. Figure 1 can be used to visualize the difference between the groups. Table 1 also revealed that the 16-18 years $(8.74 \pm 0.90)$ group was having a higher speed compared to the other two groups $(10.55 \pm 1.16,10.39 \pm 1.35)$. The One-Way ANOVA test result $(\mathrm{F}=161.85, \mathrm{p}=.00)$ (Table 3) also displays that there was a difference in mean speed between the groups, but further pairwise comparison revealed that the mean difference was significant at the 0.05 level for all pairwise comparisons except the pair 10-12 Years vs 13-15 Years. The difference can be visualized using Figure 2. Again, the endurance level of the $16-18$ years $(2.42 \pm 0.45)$ group was better compared to the groups 13-15 years $(3.56 \pm 0.58)$ and $10-12$ years $(5.44 \pm 0.83)$ (Table 2). The One-Way ANOVA test result $(\mathrm{F}=1152.52, \mathrm{p}=.00)$ further revealed the presence of a significant difference in mean endurance among the groups. A pairwise comparison also revealed the same (Figure 3). The descriptive statistics of the physical fitness variables (Table 2) further revealed that the 10-12 years group could perform an average of $11.28 \pm 3.74$ modified push-ups, 13-15 years group could perform 13.30 \pm 4.84 modified push-ups and 16-18 years could perform 14.01 \pm 4.90 modified push-ups. Though the One-Way ANOVA test result $(\mathrm{F}=17.87, \mathrm{p}=.00)$ (Table 3 ) revealed a statistically significant difference of strength between the group, the further pairwise comparison revealed that the pair 13-15 years vs 16-18 years didn't have any significant difference and that can be visualized from the Figure 4. It was also revealed that the groups 10-12 years $(15.70 \pm 5.93)$ and 13-15 years (15.36 \pm 6.62$)$ have almost similar mean flexibility whereas the 16-18 years $(12.83 \pm 4.63)$ group has lower flexibility compared to the other two groups. The One-Way ANOVA test result (Table 3) reported that there was a significant difference between the groups $(\mathrm{F}=15.69$, $\mathrm{p}=.00$ ) which was further and the pairwise test result further exhibited that the pair 10-12 Years vs 13-15 Years didn't have any significant difference (Figure 5). 
Table 1. Descriptive Statistics of Demographic Variables

\begin{tabular}{ccccccc}
\hline & & N & Mean & Std. Deviation & Minimum & Maximum \\
\hline Height & $10-12$ Years & 166 & 143.08 & 7.97 & 125 & 154 \\
(In centimetres) & 13-15 Years & 164 & 148.8 & 4.33 & 133 & 158 \\
& $16-18$ Years & 233 & 150.67 & 5.90 & 136 & 164 \\
\hline Weight & $10-12$ Years & 166 & 37.27 & 5.58 & 25 & 49 \\
$($ In KG) & $13-15$ Years & 164 & 45.41 & 4.61 & 37 & 61 \\
& $16-18$ Years & 233 & 48.97 & 3.15 & 39 & 60 \\
\hline
\end{tabular}

Table 2. Descriptive Statistics of Physical Fitness Variables

\begin{tabular}{|c|c|c|c|c|c|}
\hline & & Mean & Std. Deviation & Minimum & Maximum \\
\hline \multirow[t]{3}{*}{ BMI } & 10-12 Years & 17.93 & 1.14 & 15.09 & 20.92 \\
\hline & 13-15 Years & 20.41 & 1.74 & 17.48 & 27.77 \\
\hline & 16-18 Years & 21.58 & 1.36 & 18.2 & 25.29 \\
\hline \multirow[t]{3}{*}{ Speed } & 10-12 Years & 10.55 & 1.16 & 8.97 & 14.62 \\
\hline & 13-15 Years & 10.39 & 1.35 & 8.91 & 14.7 \\
\hline & 16-18 Years & 8.74 & 0.9 & 7.21 & 13.96 \\
\hline \multirow[t]{3}{*}{ Endurance } & 10-12 Years & 5.44 & 0.83 & 3.42 & 7.32 \\
\hline & 13-15 Years & 3.56 & 0.58 & 2.33 & 5.2 \\
\hline & 16-18 Years & 2.42 & 0.45 & 1.51 & 4.34 \\
\hline \multirow[t]{3}{*}{ Strength } & 10-12 Years & 11.28 & 3.74 & 4 & 22 \\
\hline & 13-15 Years & 13.3 & 4.84 & 3 & 26 \\
\hline & 16-18 Years & 14.01 & 4.9 & 3 & 29 \\
\hline \multirow[t]{3}{*}{ Flexibility } & 10-12 Years & 15.7 & 5.93 & 3 & 30 \\
\hline & 13-15 Years & 15.36 & 6.62 & 2 & 31 \\
\hline & 16-18 Years & 12.83 & 4.63 & 3 & 27 \\
\hline
\end{tabular}

Table 3. ANOVA table

\begin{tabular}{|c|c|c|c|c|c|c|}
\hline & & $\begin{array}{c}\text { Sum of } \\
\text { Squares }\end{array}$ & df & Mean Square & $\mathbf{F}$ & Sig. \\
\hline \multirow[t]{3}{*}{ BMI } & Between Groups & 1305.21 & 2.00 & 652.61 & 320.83 & 0.00 \\
\hline & Within Groups & 1139.1 & 560.00 & 2.03 & & \\
\hline & Total & 2444.31 & 562.00 & & & \\
\hline \multirow[t]{3}{*}{ Speed } & Between Groups & 409.43 & 2.00 & 204.72 & 161.85 & 0.00 \\
\hline & Within Groups & 708.33 & 560.00 & 1.27 & & \\
\hline & Total & 1117.77 & 562.00 & & & \\
\hline \multirow[t]{3}{*}{ Endurance } & Between Groups & 887.27 & 2.00 & 443.63 & 1152.52 & 0.00 \\
\hline & Within Groups & 215.56 & 560.00 & 0.39 & & \\
\hline & Total & 1102.82 & 562.00 & & & \\
\hline \multirow[t]{3}{*}{ Strength } & Between Groups & 746.42 & 2.00 & 373.21 & 17.87 & 0.00 \\
\hline & Within Groups & 11692.57 & 560.00 & 20.88 & & \\
\hline & Total & 12439 & 562.00 & & & \\
\hline \multirow[t]{3}{*}{ Flexibility } & Between Groups & 1004.38 & 2.00 & 502.19 & 15.69 & 0.00 \\
\hline & Within Groups & 17927.2 & 560.00 & 32.01 & & \\
\hline & Total & 18931.58 & 562.00 & & & \\
\hline
\end{tabular}




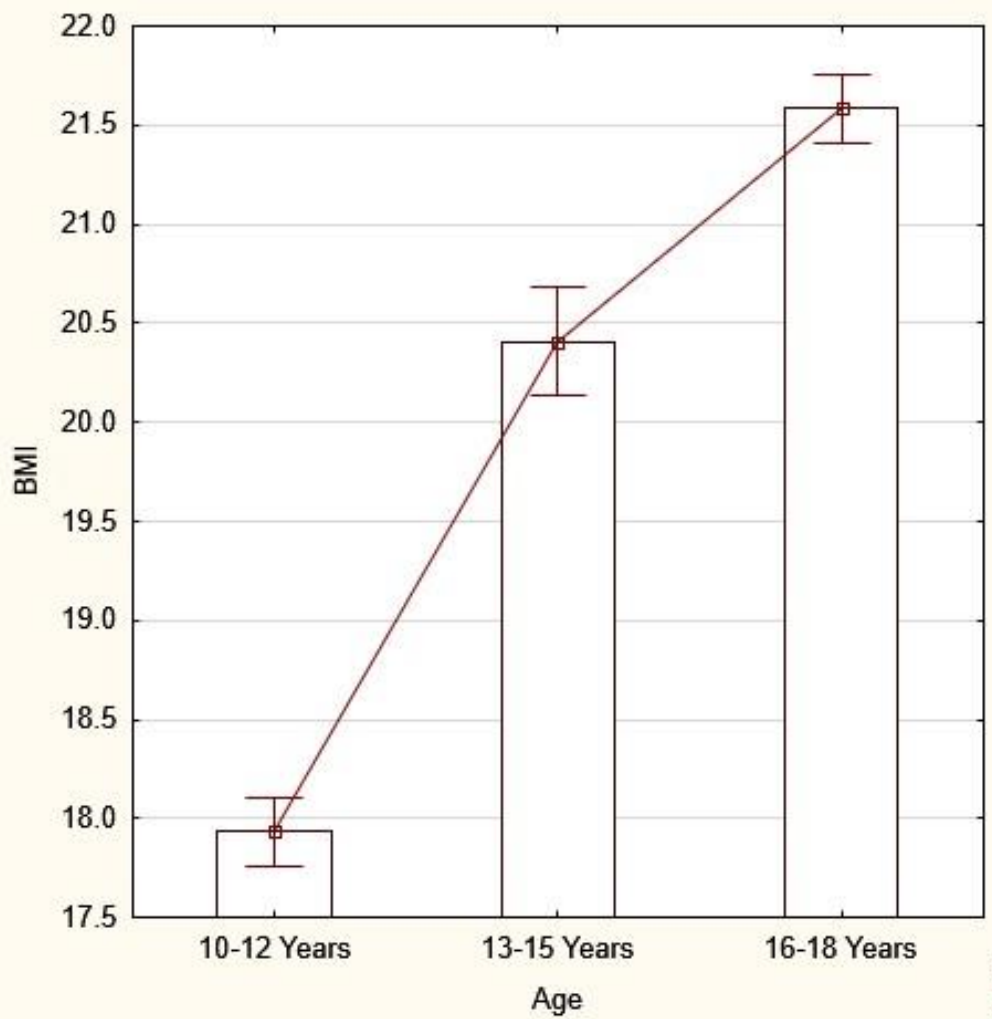

Mean

I Mean \pm 0.95 Conf. Interval

(The mean difference is significant at the 0.05 level for all pairwise comparison)

Figure 1. Mean plot of BMI

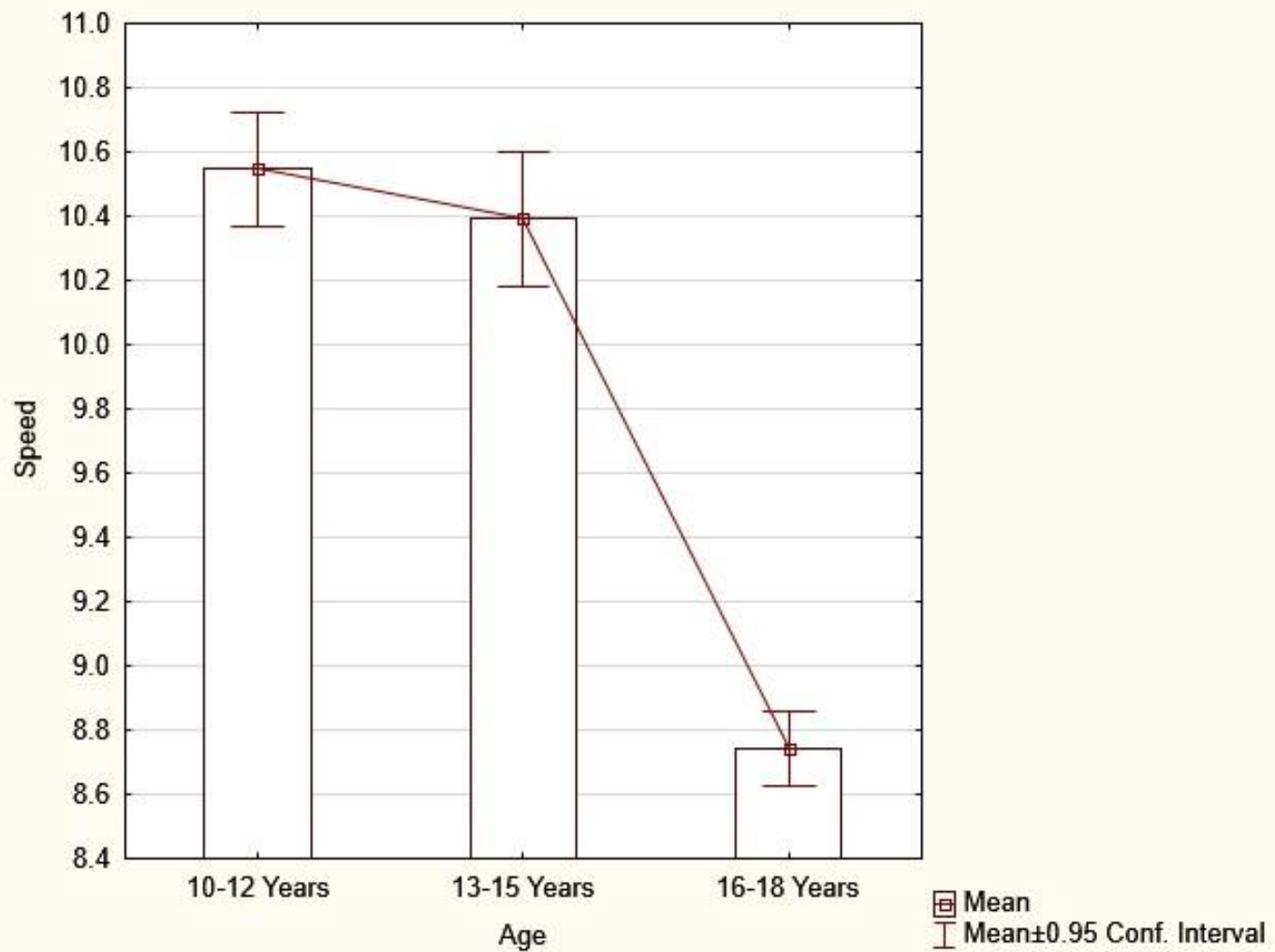

(The mean difference is significant at the 0.05 level for all pairwise comparison except the pair 10-12 Years vs 13-15 Years)

Figure 2. Mean Plot of Speed 


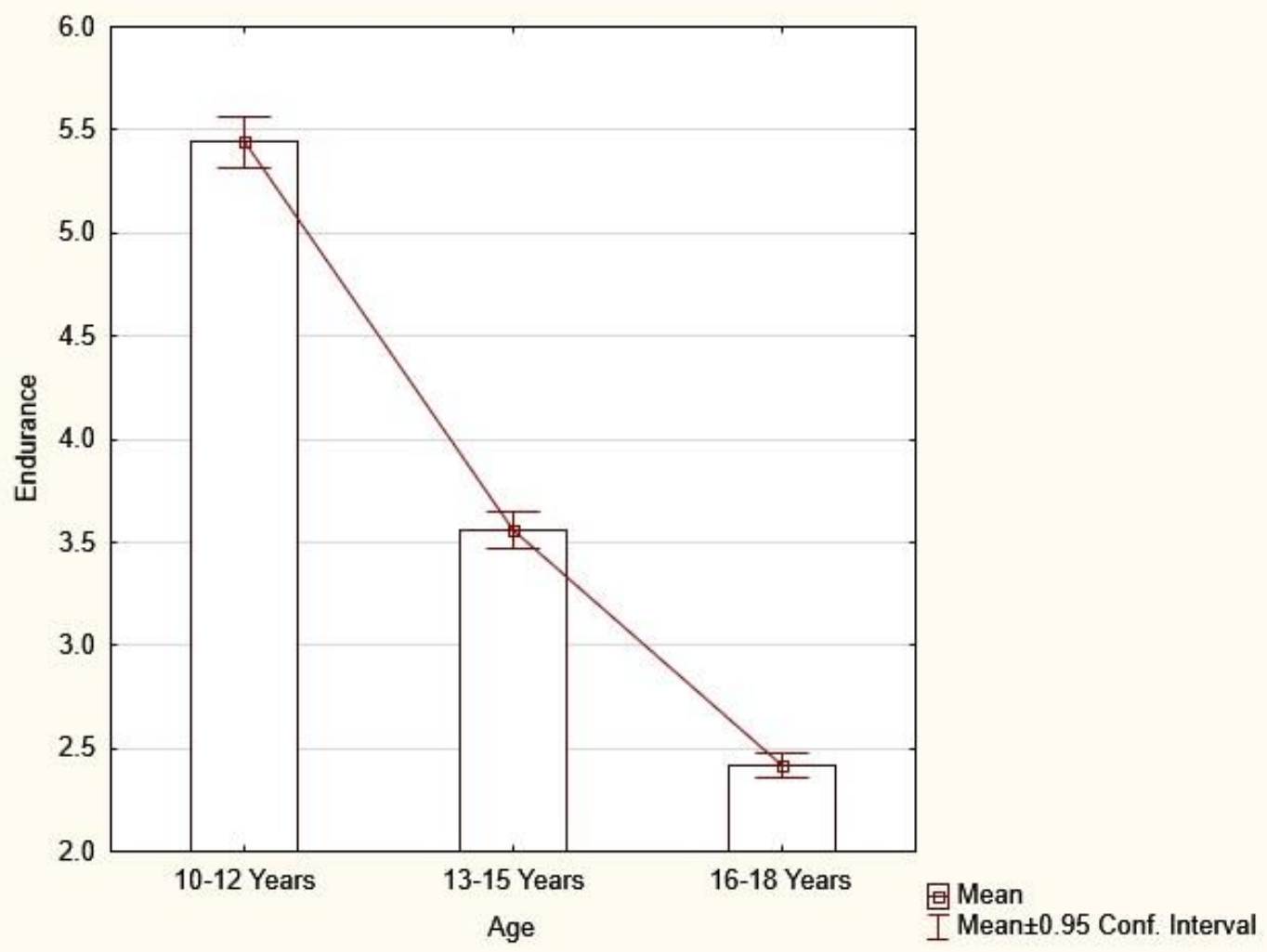

(The mean difference is significant at the 0.05 level for all pairwise comparison)

Figure 3. Mean Plot of Endurance

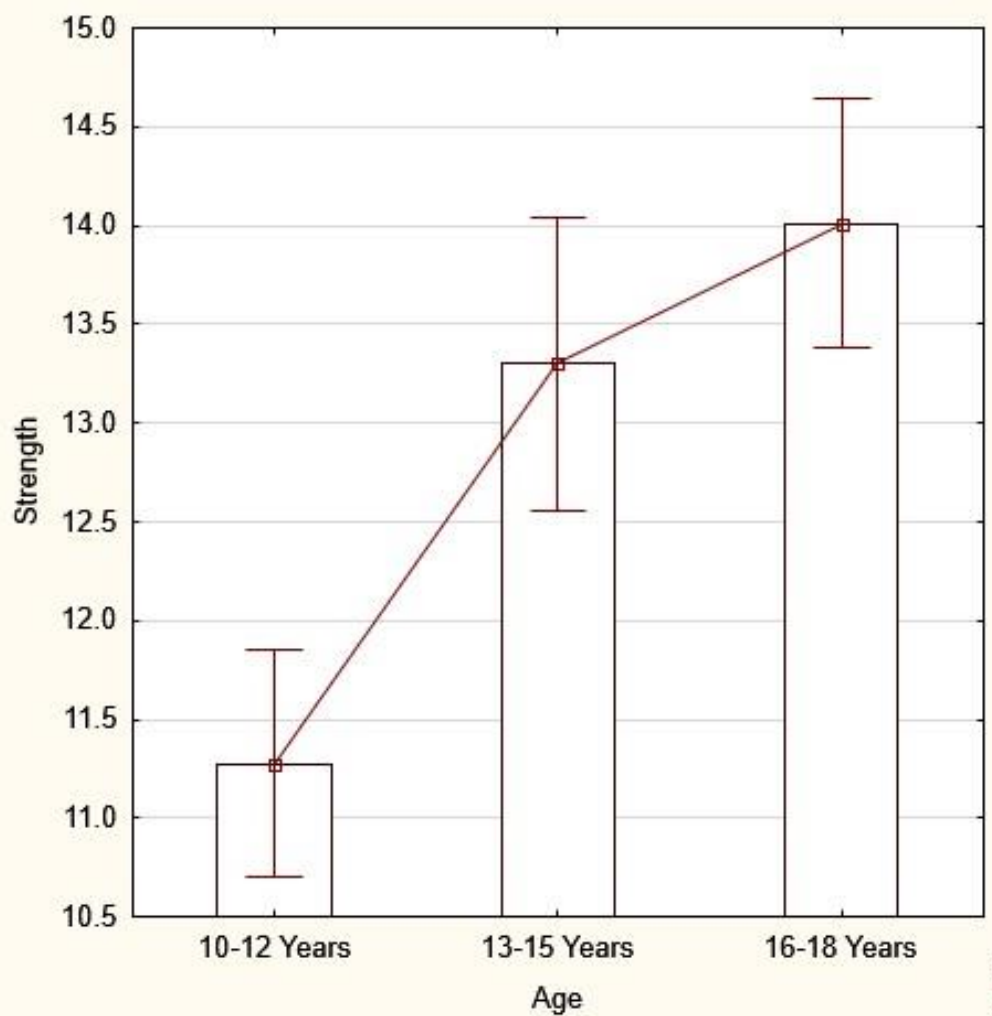




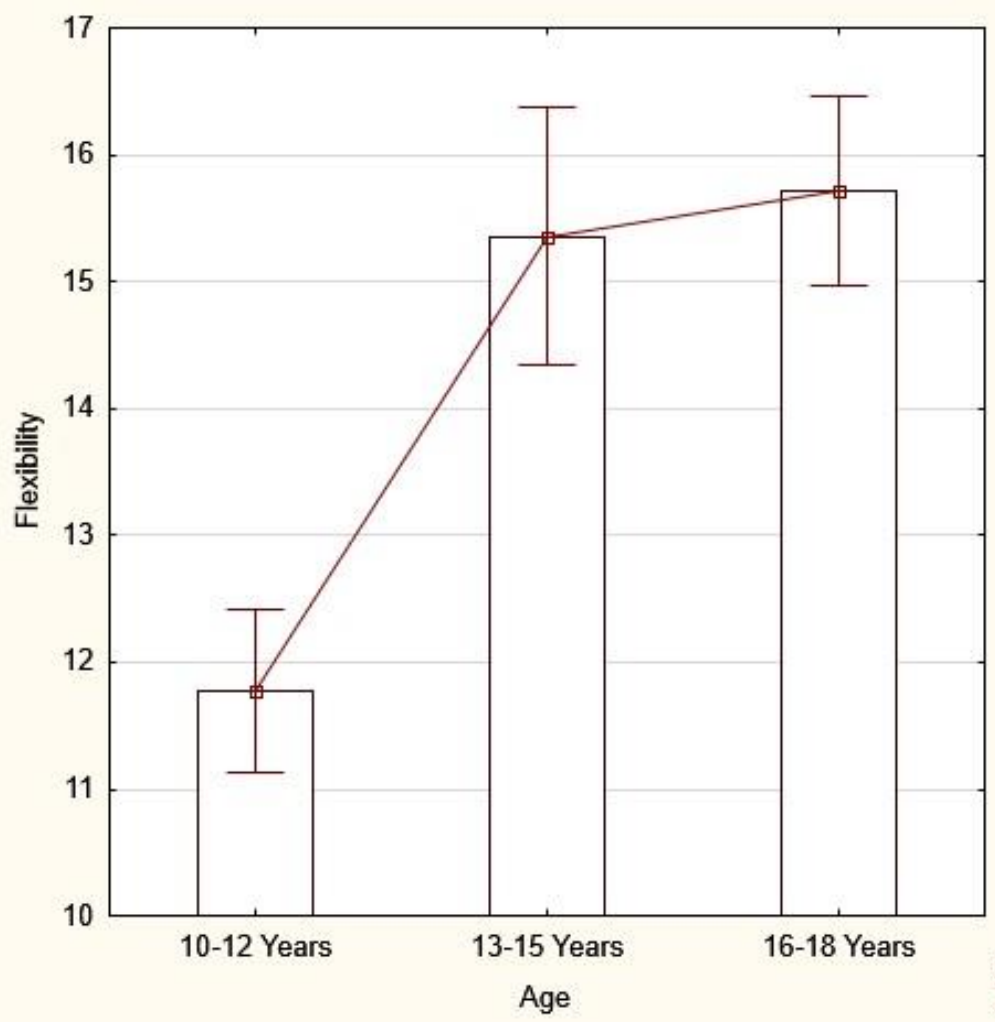

(The mean difference is significant at the 0.05 level for all pairwise comparison except the pair 10-12 Years vs 13-15 Years)

Figure 5. Mean Plot of Flexibility

\section{Discussion}

The research on health-related physical fitness highlights the information that may be incorporated in public policies to promote sports and physical activities for better health of the target population. Such research provides a comprehensive overview of fitness status indicating the overall health status of the target population to develop appropriate health promotion strategies for the policymakers. On the other hand, school health is an important component of community health service. Therefore, in this context, the present study was conducted to survey the health-related physical fitness of school going girls in the Indian Himalayan region, which will enlighten the research community as well as the local policymakers about the fitness status of the school going girl children in the Indian Himalayan region. A child's growth is not uniform and can greatly vary before reaching adulthood stage. Therefore, it is very essential to understand the trend of growth over different stages of biological age so that appropriate measures can be taken if needed. Therefore, the present study focused on understanding the health-related fitness trend as well as the differences of the health-related fitness level of the school-going girl children of the Indian Himalayan region over different biological age groups so that appropriate remedial measures can be taken as per the requirement to improve the overall fitness.

The overall result of the current study displays a moderate level of the health-related fitness of school-going girls in the Indian Himalayan region. Though the region lacks proper infrastructure for sports activities, the children's day to day activities in hilly terrain compensates for the requirement for formal induction of physical activities [19]. While comparing the results with the guideline from [20]; the result of the present study revealed that the height of the 10-12 years girls from the Indian Himalayan region falls under 50 percentile of growth data of the Indian Academy of Pediatrics (IAP). Whereas, the height of the girls of the age group 13-15 years and 16-18 years falls under the 25 percentiles. Mamidi et al. [21] had previously reported that the populations from the Himalayan region are shorter in average heights in comparison to the people of other regions of India. The current research also exhibited a similar trend while displaying the height of school-going girls in the Indian Himalayan region. On the other hand, the weight of the girls of all the age categories falls under 50 percentiles as per the growth chart of IAP. Further, the BMI of the 10-12 years girls' group was also reported to fall under the 50-percentile record for the Indian population whereas the BMI of the other two age categories falls just above the 50 percentiles. The result of the One-Way ANOVA test and pairwise comparison further revealed the presence of variance of BMI between different age groups. BMI is gender-specific. Girls display a high BMI compared to boys. A children's BMI decreases to the minimum at the 
age of 4 years and gradually increases with increasing age [22]. The result of the current study also revealed that there was no significant difference of speed between 10-12 years and 13-15 years group but 16-18 years group was having significantly higher speed compared to the other two groups. Tønnessen et al. [23] had reported that the annual speed improvement peaks from the age of 11 to 12 years with a high effect size for girls. Then the improvement gradually slows down and becomes almost plateau. Again, the improvement displays a moderate effect size between the years 15-17 years before becoming plateau between 17 and 18 years. The current research also displays a similar trend for the school going girls in the Indian Himalayan region in which their performance became plateau and exhibited no significant difference between the age groups 10-12 years and 13-15 years but there was a significant improvement when considering the age group 16-18 years. The present study also shows that the endurance level of the subjects increased significantly over increasing age. Sil [24] also reported a similar result while comparing the developmental pattern and endurance ability of school-going boys and girls. To perform endurance activities, glycogen must be stored in the muscles to convert it into glucose. With age, children develop muscles and can store more glycogen in their bodies. That is why the endurance of children increases with increasing age. According to the result, the higher age groups were having significantly higher strength compared to the age group of 10-12 years. Lowndes et al. [25] claimed that age does have a significant association with muscle size and strength in untrained young individuals. The current research also exhibited a similar trend of the girls in the Indian Himalayan region. The result shows, the age groups 10-12 years and 13-15 years have almost similar flexibility but significantly higher than the 16-18 years group. A possible reason for it may be the decreasing elasticity of ligaments and tendons with increasing ages. Another possible factor may be the increased muscle mass with age. Increased muscle mass may impair the capacity to extend the range of motion of any joints.

\section{Conclusion}

The present study displays a moderate level of health-related physical fitness of the school going girls in the Indian Himalayan region. To get good physical fitness, it is recommended to regularly participate in a planned physical activity programme. Schools can encourage the students by implementing compulsory participation in physical education classes. The latest development in online multiplayer games has a detrimental effect on children. It is developing a habit among the children to engage for hours in front of PC or Mobile, developing a sedentary lifestyle leading to poor fitness level. Such habits can be changed by the involvement of parents as well as the elders by creating an environment to engage in safe and amusing physical activities. Local parks can be developed strategically for children's physical activities or societies can hire professional physical educationists for regular physical activities of their children. A major advantage in the Indian Himalayan region is that it has plenty of open places where children can do their physical activities. Even their day-to-day activities in hilly terrains involve physical activities which have a positive effect on their overall physical fitness level. Proper execution of sports infrastructure development programs can further help in developing the health and fitness level of the population in the region.

\section{REFERENCES}

[1] Ghosh S.S., Goswami B.N., "Comparison of Basic Fitness Status Between the Children Belong to Hill Area and Coastal Area of West Bengal," Global journal for research Analysis, vol. 4, no. 12, pp. 188-189, 2015.

[2] Bull F.C., Al-Ansari S.S., Biddle S., Borodulin K., Buman M.P., Cardon G., et al., "World Health Organization 2020 guidelines on physical activity and sedentary behaviour," Br J Sports Med, vol. 54, no. 24, p. 1451, Dec. 2020, doi: 10.1136/bjsports-2020-102955.

[3] Gogoi H., Rajpoot Y.S., Sajwan A.S., "Sports Specific Injury Pattern of Sportspersons," International Journal of Human Movement and Sports Sciences, vol. 8, no. 5, pp. 199-210, 2020, doi: 10.13189/saj.2020.080507.

[4] Gogoi H., Rajpoot Y.S., Borah P., "A Prospective Cohort Study to Predict Running-Related Lower Limb Sports Injuries Using Gait Kinematic Parameters," Teoriâ ta Metodika Fìzičnogo Vihovannâ, vol. 21, pp. 69-76, Mar. 2021, doi: 10.17309/tmfv.2021.1.09.

[5] Eime R.M., Harvey J.T., Sawyer N.A., Craike M.J., Symons C.M., Payne W.R., "Changes in sport and physical activity participation for adolescent females: a longitudinal study," BMC Public Health, vol. 16, no. 1, p. 533, Jul. 2016, doi: 10.1186/s12889-016-3203-x.

[6] Sangwan J., "Participation of women in sports a case study of international sportswomen with special reference to Haryana," Maharshi Dayanand University, Rohtak, 2008. [Online]. Available: http://hdl.handle.net/10603/115689

[7] "National Education Policy 2020." Ministry of Human Resource Development, Jul. 29, 2020. Accessed: Oct. 08, 2021. [Online]. Available: https://www.education.gov.in/si tes/upload_files/mhrd/files/NEP_Final_English_0.pdf

[8] "Exposure Draft on National Physical Fitness Programme for School Children." Ministry of Youth Affairs \& Sports, Aug. 30, 2012. Accessed: Apr. 08, 2021. [Online]. Available: https://yas.nic.in/sites/default/files/File1116.pdf

[9] Ahmad Q.I., Ahmad C.B., Ahmad S.M., "Childhood obesity," Indian J Endocrinol Metab, vol. 14, no. 1, pp. 19 25, Jan. 2010

[10] Chhatwal J., Verma M., Riar S., Riar S., "Obesity among pre-adolescent and adolescents of a developing country (India)," Asia Pacific journal of clinical nutrition, vol. 13, pp. 231-5, Feb. 2004. 
[11] Gao Z., Chen S., Sun H., Wen X., Xiang P., "Physical Activity in Children's Health and Cognition," Biomed Res Int, vol. 2018, pp. 8542403-8542403, Jun. 2018, doi: $10.1155 / 2018 / 8542403$.

[12] Goyal R., Shah V., Saboo B., Phatak S., Shah N., Gohel M., et al., "Prevalence of overweight and obesity in Indian adolescent school going children: Its relationship with socioeconomic status and associated lifestyle factors," The Journal of the Association of Physicians of India, vol. 58, pp. 151-8, Mar. 2010.

[13] Terry D., Nguyen H., Perkins A. J., Peck B., "Supervision in Healthcare: A Critical Review of the Role, Function and Capacity for Training," Universal Journal of Public Health, vol. 8, no. 1, pp. 1 - 14, 2020. DOI: 10.13189/ujph.2020.080101.

[14] Turski I., Mashika H., Tkachenko T., Khmara M., Komarnitskyi I., Oliinyk M., "Medical Tourism: Analysis of the State of International Tourism and Prospects for Domestic Development," Universal Journal of Public Health, vol. 9, no. 2, pp. 27 - 34, 2021. DOI: 10.13189/ujph.2021.090201.

[15] Gogoi H., Borah P., Gogoi L., Rajpoot Y. S., Minu T., Singh J., Baro M., "A Statistical Model for Prediction of Lower Limb Injury of Active Sportsperson," International Journal of Human Movement and Sports Sciences, vol. 9, no. 6, pp. 1219 - 1229, 2021. DOI: 10.13189/saj.2021.090 616.

[16] World Medical Association, "World Medical Association Declaration of Helsinki: Ethical Principles for Medical Research Involving Human Subjects," JAMA, vol. 310, no. 20, pp. 2191-2194, Nov. 2013, doi: 10.1001/jama.2013.28 1053.

[17] "Khelo India Fitness Assessment in Schools - - version 2.0." Sports Authority of India, 2020. Accessed: Oct. 01, 2021. [Online]. Available: https://schoolfitness.kheloindia.gov.in /UploadedFiles/SampleData/AdminManual.pdf
[18] Verma J. P., Data Analysis in Management with SPSS Software, Springer, New Delhi, 2013.

[19] Sengupta P., "Assessment of Physical Fitness Status of Young Sikkimese Residing in High-Hill Temperate Regions of Eastern Sikkim under the Influence of Climate and Socio-Cultural Factors," Asian Journal of Medical Sciences, vol. 2, May 2012, doi: 10.3126/ajms.v2i3.5368.

[20] Khadilkar V., Yadav S., Agrawal K., Tamboli S., Banerjee M., Cherian A., et al., "Revised IAP Growth Charts for Height, Weight and Body Mass Index for 5- to 18-year-old Indian Children," Indian pediatrics, vol. 52, pp. 47-55, Jan. 2015, doi: 10.1007/s13312-015-0566-5.

[21] Mamidi R., Kulkarni B., Singh A., "Secular Trends in Height in Different States of India in Relation to Socioeconomic Characteristics and Dietary Intakes," Food and nutrition bulletin, vol. 32, pp. 23-34, Mar. 2011, doi: $10.1177 / 156482651103200103$.

[22] "Using the BMI-for-Age Growth Charts." Centre for Disease Control and Prevention, Sep. 09, 2014. Accessed: Oct. 08, 2021. [Online]. Available: https://www.cdc.gov/nccdphp/dnpa/growthcharts/training/ modules/module1/text/module1print.pdf

[23] Tønnessen E., Svendsen I.S., Olsen I.C., Guttormsen A. Haugen T., "Performance development in adolescent track and field athletes according to age, sex and sport discipline," PLoS One, vol. 10, no. 6, pp. e0129014-e0129014, Jun. 2015, doi: 10.1371/journal.pone.0129014.

[24] Sil P., "Developmental Perspective of Endurance Ability among School- Going Boys and Girls: A Comparative Analysis," International Journal of Research and Review, vol. 3, no. 6, pp. 43-46, 2016.

[25] Lowndes J., Carpenter R.L., Zoeller R.F., Seip R.L., Moyna N.M., Price T.B., et al., "Association of age with muscle size and strength before and after short-term resistance training in young adults," J Strength Cond Res, vol. 23, no. 7, pp. 1915-1920, Oct. 2009, doi: 10.1519/JSC.0b013e3181b94b35. 